\title{
Future of seafood under climate change
}

\section{CHRIS FREE}

Ocean fisheries and aquaculture are highly vulnerable to climate change but many negative impacts could be reversed or mitigated through effective adaptations. In this talk, I will describe how climate change has already altered marine fisheries and aquaculture and the lessons learned for enhancing resilience to future change. I will then present national-scale projections of the impact of future climate change and alternative climate change adaptations on fisheries and aquaculture. I identify countries that (1) could see gains in food and profits with adaptations, (2) could offset losses in capture fisheries through the expansion of ocean aquaculture; and (3) are likely to suffer inevitable losses in food from the ocean. I will conclude with recommendations for effectively and equitably adapting each type of national ocean food system to climate change. 